although caution should be applied if extrapolating this data to low prevalence settings. Poor confirmation rates from throat specimens is probably due to cross-reactivity with commensal Neisseria, and highlights confirmation is essential when testing these samples.

\begin{tabular}{|c|c|c|c|c|}
\hline & $\begin{array}{l}\text { Genital Swab } \\
\text { (Female) } \\
{[\mathrm{n}=119]}\end{array}$ & $\begin{array}{l}\text { Urine } \\
\text { (Male) } \\
{[\mathrm{n}=84]}\end{array}$ & $\begin{array}{l}\text { Rectal } \\
{[n=97]}\end{array}$ & $\begin{array}{l}\text { Throat } \\
{[n=694]}\end{array}$ \\
\hline $\begin{array}{l}\text { Probetec GC } \\
\text { Qx (Becton } \\
\text { Dickinson) }\end{array}$ & $78.7 \%(37 / 47)$ & $94 \%(47 / 50)$ & $85.1 \%(23 / 27)$ & $44.2 \%(248 / 587)$ \\
\hline $\begin{array}{l}\text { Cobas } \\
\text { Amplicor } \\
\text { (Roche) }\end{array}$ & $83.3 \%(50 / 60)$ & $91.3 \%(21 / 23)$ & $79.4 \%(27 / 34)$ & $48.2 \%(27 / 56)$ \\
\hline $\begin{array}{l}\text { RealTime } \\
\text { CT/NG (Abbott) }\end{array}$ & $83.3 \%(10 / 12)$ & $72 \%(8 / 11)^{*}$ & $80.5 \%(29 / 36)$ & $88.2 \%(45 / 51)$ \\
\hline
\end{tabular}

\section{O25 USE OF CEFTRIAXONE AND DOXYCYCLINE WHEN TREATING GONORRHOEA: IS IT PRESCRIBED APPROPRIATELY?}

John Were*, Katy Town, Hamish Mohammed, John Saunders, Stephanie Chisholm, Helen Fifer, Gwenda Hughes. Public Health England, London, UK

\subsection{6/sextrans-2015-052126.25}

Background National gonorrhoea treatment guidelines recommend ceftriaxone with azithromycin as first-line therapy, but doxycycline is recommended instead of azithromycin for patients with gonococcal pelvic inflammatory disease (PID). In 2013, $86.5 \%$ of patients in the Gonococcal Resistance to Antimicrobials Surveillance Programme (GRASP) were treated with the recommended therapy, but $3.9 \%$ were treated with doxycycline instead of azithromycin.

Objectives The objective of this analysis was to determine whether ceftriaxone plus doxycycline were prescribed for appropriate indications.

Methods Using GRASP 2013 data, patients prescribed the recommended therapy were compared with patients prescribed ceftriaxone and doxycycline, and associations were assessed using univariate and multivariate logistic regression.

Results In 2013, of the 913 patients prescribed ceftriaxone and azithromycin, $45.9 \%$ were men who have sex with men (MSM), $20 \%$ were women and $34.1 \%$ were heterosexual men while, of the 45 patients prescribed ceftriaxone and doxycycline, $64.4 \%$ were MSM, 28.9\% were women and 6.7\% were heterosexual men $(\mathrm{p}=0.001)$. Of those prescribed ceftriaxone and doxycycline, 22.2\% were MSM with chlamydia co-infection and 17.7\% were women with PID. On multivariate analysis, MSM coinfected with chlamydia (aOR 3.4, 95\% CI, 2.5-4.6; $\mathrm{p}=0.001$ ) and women diagnosed with gonococcal PID (OR,144.8, 95\% CI, 24.2-864.0; p < 0.001) were more likely to be prescribed ceftriaxone and doxycycline.

Conclusion Less than a fifth of prescriptions for ceftriaxone with doxycycline were issued to treat gonococcal PID. Use of ceftriaxone with doxycycline may be preferred to treat MSM coinfected with chlamydia by some clinicians. However, as levels of tetracycline resistance in gonorrhoea are high, this may not provide the dual treatment coverage required.
026 GONORRHOEA TEST-OF-CURE BY POST MAINTAINS RETURN RATE

Daniel Dennehy, Gary Whitlock, Sheel Patel, Alan McOwan, Nneka Nwokolo*. Chelsea \& Westminster Hospital, 56 Dean Street, London, UK

\subsection{6/sextrans-2015-052126.26}

Background/introduction BASHH guidelines recommend test-ofcure (TOC) in all cases of $N$. gonorrhoeae (NG) 2 weeks after treatment. Previously patients re-attended our clinic in person for TOC. To create capacity in the clinic, we introduced NG TOC postal packs for MSM following treatment.

Aim(s)/objectives To evaluate TOC return rate and patient satisfaction with the service development.

Methods MSM with proven NG were given postal TOC packs at treatment. Each pack contains appropriate NAAT sampling kits for site of diagnosed infection (rectal, throat, urine) and written instructions, patient satisfaction survey and partner notification questionnaire. Patients are instructed to return TOC samples by post in a provided Royal Mail Safebox. We processed samples using our in-house GeneXpert system; results are sent by SMS.

Results During November 2014, 136 NG TOC packs were dispensed. 76 (55.9\%) patients returned postal packs; 28 (20.6\%) attended for TOC in person, giving overall TOC rate, $76.5 \%$. NG TOC rate in October 2014 was 75.8\%. The median time from treatment to sending TOC results was $19 \mathrm{~d}$ (IQR:16-24d). NG TOC positivity rate was $12.5 \%$ (13/104). 65 patient satisfaction surveys were returned. Most responders found postal TOC easy to use $(81.5 \%$; 53/65). 24.6\% (16/65) responders would have preferred to attend in person for TOC.

Discussion/conclusion Postal testing is an acceptable NG TOC method which, when combined with the option to return in person, reduced unnecessary follow-up visits while maintaining TOC return rate. The high TOC positivity rate reinforces the importance of continuing to retest patients with NG after treatment.

\section{HIGH RATES OF MACROLIDE RESISTANCE IN MYCOPLASMA GENITALIUM}

Rachel Pitt, Sarah Alexander*. Public Health England, London, UK

\subsection{6/sextrans-2015-052126.27}

Background/introduction Macrolide resistance has been previously reported in Mycoplasma genitalium (MG), however due to limited diagnostics, studies have been mainly restricted to specific geographical areas and small numbers of positive samples.

Aim(s)/objectives To determine the rate of macrolide resistance in $\mathrm{MG}$ specimens.

Methods Eighty-five MG positive specimens (72 from males, 13 from females) that had been referred for MG centralised testing (between 2010-2014), from 17 centres across England and Wales were blinded and anonymised. Specimens were then examined using a 23S rRNA PCR followed by full DNA sequence analysis. The Chi Square test was used to compare data sets.

Results $23 S$ rRNA PCR was successful in $86 \%(73 / 85)$ of specimens. Of the specimens examined, $84 \%(61 / 73)$ harboured single nucleotide polymorphisms (SNP) associated with macrolide resistance (Table 1). Significant differences were observed between the rates of macrolide resistance in male [95\% (58/61)] and female $[25 \%(3 / 12)]$ patients $[\mathrm{P}=<0.001]$. Twelve 